\title{
VAPOR ADSORPTION TRANSIENT TEST FACILITY FOR DEHUMIDIFICATION AND DESORPTION STUDIES
}

\author{
Mohsen Shakouri ${ }^{2}$, Easwaran N. Krishnan ${ }^{2}$, Leila Dehabadi ${ }^{1}$, Abdalla H. Karoyo ${ }^{1}$, Carey J. \\ Simonson $^{2}$, Lee D. Wilson ${ }^{*}$ \\ ${ }^{1}$ Department of Chemistry, University of Saskatchewan, 110 Science Place, Saskatoon, SK S7N 5C9, \\ Canada \\ ${ }^{2}$ Department of Mechanical Engineering, University of Saskatchewan, 57 Campus Drive, Saskatoon, \\ SK S7N 5A9, Canada
}

(Received: May 2018 / Revised: June 2018 / Accepted: October 2018)

\begin{abstract}
The steady state performance testing of industrial-scale energy wheels requires large-scale and advanced instrumentation to analyze large volumes of data. In order to address the feasibility of laboratory-scale studies, experimental modelling and data simulation have been successfully performed by means of the transient and cyclic testing of a heat exchanger within an energy wheel setup in a parallel-flow air stream configuration. However, major challenges have been encountered in terms of predicting the effectiveness of a counter-flow energy wheel configuration in different operating conditions via the use of a transient test setup in a parallel-flow configuration. In the present study, we report the modification of a transient test facility intended to facilitate the more accurate simulation of a full-scale energy wheel operation in a small-scale test facility. A new test section was designed to: (1) enable tests in both counter-flow and parallelflow configurations; (2) afford automated cyclic testing and achieve the reliable simulation of the energy wheels dehumidification/regeneration cycles; and (3) enhance the accuracy and reduce the uncertainty of the relative humidity $(\mathrm{RH})$ measurements through utilization of the bag sampling method. The latter method is shown to yield greater accuracy with regard to the RH in non-isothermal operating conditions, as well as to reduce the data processing required for the estimation of latent effectiveness.
\end{abstract}

Keywords: Bio-desiccants; Energy/heat wheel; Latent effectiveness; Starch particles; Water vapor

\section{INTRODUCTION}

In North America, there is increasing demand for greater energy efficiency due to the rising costs of both heating and cooling in residential and industrial buildings alike. Based on population growth and climate change projections, energy consumption is forecast to increase (ca. 30\%) over the course of this century. For this reason, heating, ventilation, and air-conditioning (HVAC) systems that incorporate air-to-air energy exchangers (AAEEs) have been designed to provide significant energy savings between the intake and exhaust air streams for buildings with an external environment. A key feature of these AAEEs is the energy wheel, which employs a rotating metallic wheel with a desiccant coating to recover moisture and latent heat from the two air streams during the exchange between indoor and outdoor air supplies.

\footnotetext{
*Corresponding author's email: lee.wilson@usask.ca, Tel. +1-306-966-2961, Fax. +1-306-966-4730

Permalink/DOI: https://doi.org/10.14716/ijtech.v9i6.2302
} 
In order to overcome the challenges associated with the infrastructure and operational costs of research concerning large-scale industrial energy wheels, an alternative approach has been developed (Abe et al., 2006a; Abe et al., 2006b; Shang \& Besant, 2009a; Shang \& Besant, 2009b; Fathieh et al., 2015). Fathieh et al. (2015) demonstrated the general utility of the transient test facility at the University of Saskatchewan, as well as its utility in terms of the simulation of key parameters for large-scale AAEEs. Transient tests that use a small-scale heat exchanger were performed to predict the latent effectiveness of an energy wheel with the same matrix geometry, materials, and coating pattern in order to overcome the need for a full-scale wheel. The full-scale testing protocol involves the removal and replacement of the desiccant coating, the re-sealing of the casing, external driving systems, and air ducts. By contrast, the small-scale transient test device circumvents these requirements. In particular, the transient dehumidification and regeneration measured using the small-scale test facility revealed that the latent effectiveness of large-scale energy wheels was accurately predicted with comparable geometry and coating (Fathieh et al., 2016). The latent effectiveness of the systems varied depending on the angular speeds, air flow rates, and the level/type of coating on the metal substrate of the exchanger.

Our group has demonstrated a significant improvement in the latent effectiveness of the exchanger according to the nature of the desiccant coating, as shown by the significant differences between silica gel particles with variable textural properties and high-amylose starch biopolymers (Fathieh et al., 2015; Fathieh et al., 2016; Dehabadi et al., 2017; Hossain et al., 2018). The higher rate of sorption and the increased uptake capacity of high-amylose starch (HAS) per unit mass have been shown to exceed those of silica gel materials. Further studies have found that the regeneration process for a starch-coated energy wheel is effective, which has led to the further investigation of both HAS (Fathieh et al., 2015; Dehabadi et al., 2017) and carnation starch (Vaccaria hispanica, syn. Saponaria vaccaria) (Hossain et al., 2018) as promising desiccant materials for full-scale AAEEs.

Despite the benefits offered by the small-scale transient test facility, one key limitation of the test system relates to the simulation of the rapid oscillation of air sampling between dual air channels that differ in terms of their humidity and temperature conditions via a single channel operating mode. In the present study, we report on a recently designed improvement to the transient test facility that affords greater experimental research capacity over wider operating conditions that are relevant to large-scale energy wheels. In particular, it offers the ability to sample dual channel streams rapidly and with greater sensitivity with regard to variable temperature and relative humidity changes, both before and after passage across the desiccant coating material. We anticipate that the results obtained using this experimental test facility will contribute significantly to advanced research and development concerning industrial AAEEs.

\section{BACKGROUND AND METHODOLOGY}

An energy wheel is used for energy recovery as an AAEE. Energy wheels consist of a large number of circular honeycomb channels coated with desiccant materials, which exhibit suitable textural properties (surface area and pore structure). AAEEs are commonly used to transfer sensible (heat) and latent (moisture) energy between two air streams in a counter-flow arrangement, where one stream is hot and humid, while the other stream is cold and dry. An illustration of an energy wheel is presented in Figure 1. The performance of such desiccant-coated energy wheels is commonly evaluated by determining their latent or sensible effectiveness using experimental, numerical modelling, and simulation data.

To date, the experimental approaches involving modelling remain promising approaches for the investigation of the latent effectiveness of energy wheels. Standard tests exist for the steady-state performance testing of full-scale energy wheels (ANSI/ASHRAE, 2013; ANSI/AHRI, 2014; 
CSA Group, 2018). Despite the advantages offered by the full-scale energy wheel test method, other reports concerning steady state testing have shortcomings due to the high operational cost and complex experimental design. Therefore, a simplified, accurate, and reliable test method is desired to facilitate the reliable prediction of energy wheel performance in laboratory-scale test facilities. Our group has proposed a test method for determining the effectiveness of an energy wheel by evaluating the transient response of that wheel to a single step-change in the inlet flow properties, such as the temperature and/or relative humidity (Abe et al., 2006a; Abe et al.,2006b; Shang \& Besant, 2009a; Shang \& Besant, 2009b; Fathieh et al., 2015). The proposed method is straightforward, and it has a lower associated cost when compared to the steady-state (full-scale) testing methods. Using this approach, Fathieh et al. (2015, 2017) and Hossain (2018) developed a novel transient test facility for predicting the effectiveness of energy wheels in variable operating conditions. The facility enabled transient testing in a parallel-flow (PF) air stream using a small-scale energy exchanger.

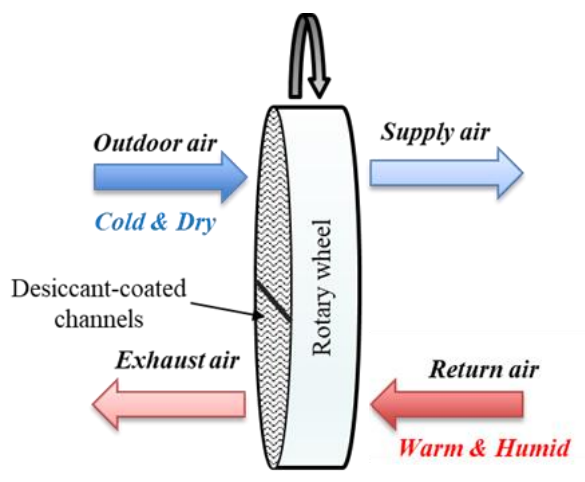

Figure 1 Schematic of a typical energy wheel with supply and exhaust air streams

\subsection{Background Theory and Model Equations}

\subsubsection{Transient step-change theory}

Effectiveness is the most important quantitative parameter for evaluating the performance of rotary wheels. The moisture recovery performance is described by the latent effectiveness $(\epsilon)$, and it refers to the ratio of the actual moisture transfer rate to the maximum possible moisture transfer rate between dry and humid air streams. Additionally, $\epsilon$ can be cast as a function of the number of mass transfer units $\left(N T U_{m}\right)$. The latent effectiveness of an energy wheel with a counterflow $(\mathrm{CF})$ configuration is defined in Equation 1, where the supply air streams are balanced and $N T U_{m}$ is the number of transfer units (Shah \& Sekulic, 2003).

$$
\epsilon_{C F}=\frac{N T U_{m}}{1+N T U_{m}}
$$

Fathieh et al. (2015) derived an equation for determining the $N T U_{m}$ from the humidity profile of an exchanger, with Equation 2 showing an analytical relation for the calculation of the $N T U_{m}$ by considering the two modes of mass transfer between air streams and desiccant particles. In the transient testing setup, the $N T U_{m}$ is defined as a function of the wheel's rotational speed $(\omega)$, a time constant $(\tau)$, and a weighting factor $(\gamma)$.

$$
N T U_{m}=-\frac{1}{2} \operatorname{Ln}\left\{1-\sum_{i=1}^{2}\left(\frac{2 \omega}{\pi}\right) \gamma_{i} \tau_{i} \frac{\left(1-e^{\frac{-\pi}{\omega \tau_{i}}}\right)^{2}}{\left(1-e^{\frac{-\pi}{\omega \tau_{i}}}\right)}\right\}
$$


The transient step-change response of an energy exchanger can be expressed using a double exponential model and a time constant $(\tau)$ with weighting factors $(\gamma)$. The parameters can be determined by fitting the double exponential model to the experimental data, as described by Equations 3 and 4, where $W(t)$ is the normalized humidity ratio response of the exchanger at time t.

$$
\begin{gathered}
W(t)=1-\gamma_{1} e^{\frac{-t}{\tau_{1}}}-\gamma_{2} e^{\frac{-t}{\tau_{2}}}, \quad 0 \leq t \leq \infty, \text { (step increase/adsorption/dehumidification) } \\
W(t)=\gamma_{1} e^{\frac{-t}{\tau_{1}}}+\gamma_{2} e^{\frac{-t}{\tau_{2}}}, \quad 0 \leq t \leq \infty, \text { (step decrease/desorption/regeneration) }
\end{gathered}
$$

Thus, the $N T U_{m}$ term for the various rotational speeds of an energy wheel $(\omega)$ can be predicted by Equation 2, while the corresponding $\epsilon_{C F}$ can be calculated by Equation 1.

\subsubsection{Steady-state cyclic tests theory}

The latent effectiveness of energy wheels can also be determined by conducting repeated cyclic experiments using a PF test section. In this case, the latent effectiveness is expressed as the ratio of the amount of moisture recovered during half of the $\mathrm{n}^{\text {th }}$ cycle $\left(\mathrm{W}_{\text {humid }}-\mathrm{W}_{\text {initial }}\right)$ to the maximum possible moisture transfer between the dry and humid air streams $\left(\mathrm{W}_{\text {humid }}-\mathrm{W}_{\text {dry }}\right)$. By using the humidity profile of the exchanger outlet, the latent effectiveness when in a PF configuration $\left(\epsilon_{P F}\right)$ can be expressed by Equation 5 .

$$
\epsilon_{P F}= \begin{cases}\frac{\omega}{\pi} \int_{n}^{n+\frac{\tau}{2}}(1-W) d t & \text { dehumidification } \\ \frac{\omega}{\pi} \int_{n+\frac{\tau}{2}}^{\tau}(W) d t & \text { regeneration }\end{cases}
$$

Then, the $N T U_{m}$ can be determined based on the effectiveness- $N T U_{m}$ relation of a PF heat exchanger using Equation 6 (Fathieh et al., 2016).

$$
N T U_{m}=-\frac{1}{2} \operatorname{Ln}\left(1-2 \epsilon_{P F}\right)
$$

Since the $N T U_{m}$ is independent of the flow configuration, Equation 1 can also be used to estimate the effectiveness of the same energy exchanger with a CF arrangement. It should be noted that the uncertainty in the latent effectiveness of the $\mathrm{CF}$ energy exchanger is evaluated by propagating the uncertainty associated with the PF test condition.

\subsection{Transient Test Facility Modification}

Previous studies have indicated that there are four key challenges associated with the prediction of the latent effectiveness of CF energy wheels at variable operating conditions when using the transient test section with a PF configuration. First, energy wheels do not work with a PF arrangement. Second, in cyclic experiments, the exchanger is manually subjected to multiple dehumidification (adsorption) and regeneration (desorption) cycles. Thus, it is not practical to simulate the typical condition of energy wheels that commonly operate for many cycles and longer periods. Third, a large degree of uncertainty results from multiple dehumidification and regeneration cycles, which leads to the narrowing of the valid test range of the experiment. Fathieh et al. (2016) showed that the propagated uncertainty would be very high (ca. 30\%) for selected operating conditions when seeking to predict the effectiveness of a CF energy wheel based on the small-scale PF test section. This relates to the exponential relation between the latent effectiveness and the $N T U_{m}$ (Equation 6). Therefore, this testing methodology will not provide accurate results with acceptable uncertainty levels for all operating conditions. Fourth, due to the slow response time of the relative humidity sensors, either pressure/humidity swing (isothermal 
outdoor and return air streams with variable relative humidity) or temperature swing (constant relative humidity for outdoor and return air streams with variable humidity content) tests can be evaluated. Wang et al. (2007) found that T-type thermocouples exhibit a rapid response to a stepchange ( 3 to $5 \mathrm{~s}$ ) in temperature. However, humidity sensors exhibit a slower response time when the temperature and $\mathrm{RH}$ change simultaneously (180 to $300 \mathrm{~s}$ in non-isothermal conditions). Since the rotational speed of energy wheels is generally within the range of 10 to $20 \mathrm{rpm}(\approx 6$ to $3 \mathrm{~s}$ during linear motion periods), it is not feasible to measure accurate RH values for the air leaving the exchanger over a short period of time using commercially available RH sensors.

In order to address the above issues, as well as to ensure reliable and reproducible operating conditions for the energy wheels, the following modifications to the transient test section with a PF configuration (TTS-PA) were made: (1) a test section modification for the CF arrangement; (2) the fabrication of a cycle generator unit to simulate reliable cyclic tests of the energy wheel; and (3) the development of a method for reducing the RH measurement uncertainty so as to enable simultaneous temperature and humidity swing testing. Thus, a new transient test section with a $\mathrm{CF}$ arrangement (TTS-CF) was designed and fabricated, and Figure 2 shows a schematic illustration of the new test section with a CF configuration.

The air ducts I and II are the inlet streams, which are designed to enable the CF air supply. In order to provide a uniform velocity profile, an additional flow channel was placed in each air stream prior to the exchanger inlet. The temperature and $\mathrm{RH}$ were measured on the upstream and downstream sides of the exchanger. A cycle generator unit (CGU) was also designed to move the exchanger between the two air streams, and consequently, to subject the parallel-plate exchanger to continuous dehumidification and regeneration cycles. The CGU allows for the accurate simulation of the actual operating conditions of an energy wheel using the small-scale facility described here. The linear actuators within the CGU are capable of moving the exchanger's frame box through the horizontal guide rails at the desired speed between the hot and cold air streams. The rails and the cartridges are attached to the interior of the PVC box and the exterior of the exchanger frame box, respectively, as shown in Figure $2 b$. The actuators are controlled by a signal-board microcontroller in order to enable various cycle frequencies, for periods as low as $1000 \mathrm{~ms}$, based on the wheel's operating range. Table 1 summarizes the capability of the new test section when compared to the original setup.

Table 1 Comparison between the old and the modified test sections

\begin{tabular}{lcc}
\hline \multicolumn{1}{c}{ Capability } & Old Test Section & Modified Test Section \\
\hline Parallel-flow arrangement & $\mathrm{Y}$ & $\mathrm{Y}$ \\
Counter-flow arrangement & N/A & Y \\
Cycle generator unit & N/A & Y \\
Cyclic test & Analog; manual & Dynamic; automatic \\
Accuracy of the cyclic test periods & Limited to manual control & $\sim 10^{2} \mathrm{~ms}$ \\
Time required for RH measurements & 180 to $300 \mathrm{~s}$ & $\sim 10^{1} \mathrm{~s}$ \\
\hline
\end{tabular}

As mentioned above, a cyclic test of a small- or full-scale energy exchanger requires sensors capable of giving a rapid response. Due to the periodic fluctuations in the humidity and/or temperature of the air streams, the uncertainty of the $\mathrm{RH}$ measurements obtained using commercial sensors indicates that the values are not reliable. A bag sampling method (BSM) was proposed to determine the average outlet conditions in air-to-air heat/energy exchangers where rapid sensors are not available (CSA Group, 2018). Using this method, the wet-bulb or dew-point temperature of the leaving air stream is determined in order to allow time for the RH sensor to attain equilibrium. Thus, a precise determination of the RH content of the outlet air stream (supply or exhaust air streams, as shown in Figure 1) can be obtained. Moreover, when compared to the 
transient testing measurements, the BSM provides a direct approach for considering the realistic steady-state performance of industrial energy wheels. In other words, there is no need to determine the latent effectiveness of the energy wheel by using data fitting and calculating the transient system response ( $c f$. Equations 2 to 6 ). The latent effectiveness $(\epsilon)$ can be calculated directly using Equation 7, where $W$ represents the water content of the air streams.

$$
\epsilon=\frac{\left(W_{\text {outdoor }}-W_{\text {supply }}\right)}{\left(W_{\text {outdoor }}-W_{\text {return }}\right)}
$$

An illustration of a bag sampler configuration is presented in Figure 3. After the system reaches a steady-state, a vacuum created in the box draws air into the sampling bag without drawing it through the vacuum pump. This prevents the contamination of the sample. The humidity of the sample can then be analyzed, albeit only after it has reached equilibrium (not less than 5 mins). In order to avoid condensation, a heater is placed so as to keep the temperature inside the chamber approximately $5-10^{\circ} \mathrm{C}$ higher than the temperature of the dew point of the humid air stream.
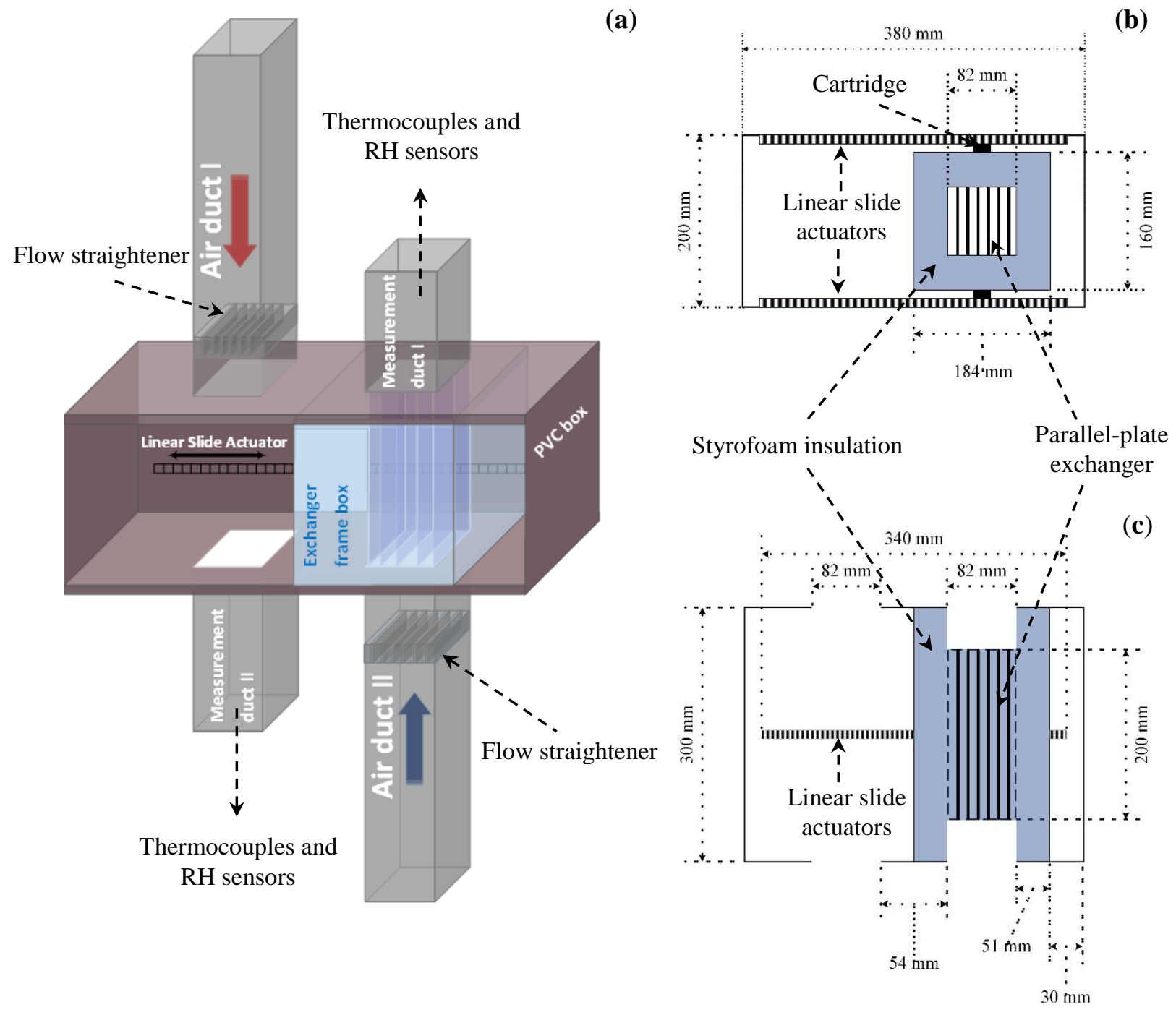

Figure 2 Schematic illustration of the test section for a CF arrangement with a moving parallel-plate heat exchanger: (a) overall perspective; (b) top view; and (c) front view 


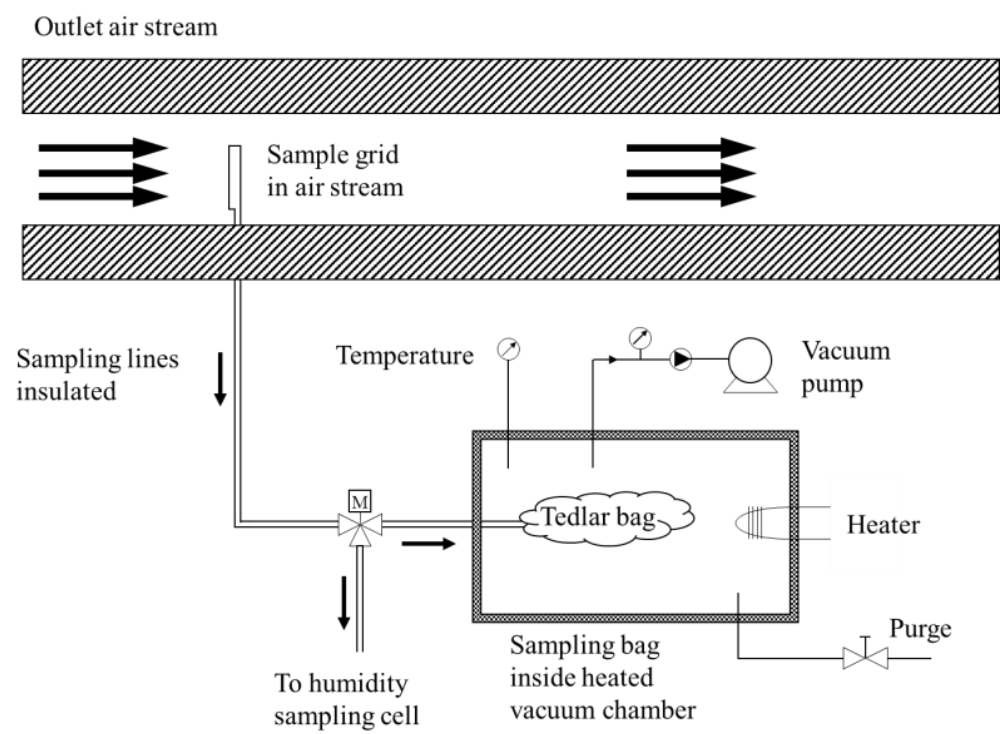

Figure 3 Schematic of the experimental setup for the bag sampling method (BSM) (CSA Group, 2018)

\subsection{Experiment Methodology and Procedure}

A schematic of the test facility with the TTS-CF is shown in Figure 4, which consists of a supply air system whereby a compressor is combined with a dehumidifier. The test conditions are simulated using the humidifier, mass-flow controllers, and heaters. The air stream temperature and RH can be varied in order to simulate the flow conditions in energy wheels, where the parameters are measured in the test section (Figure 2).

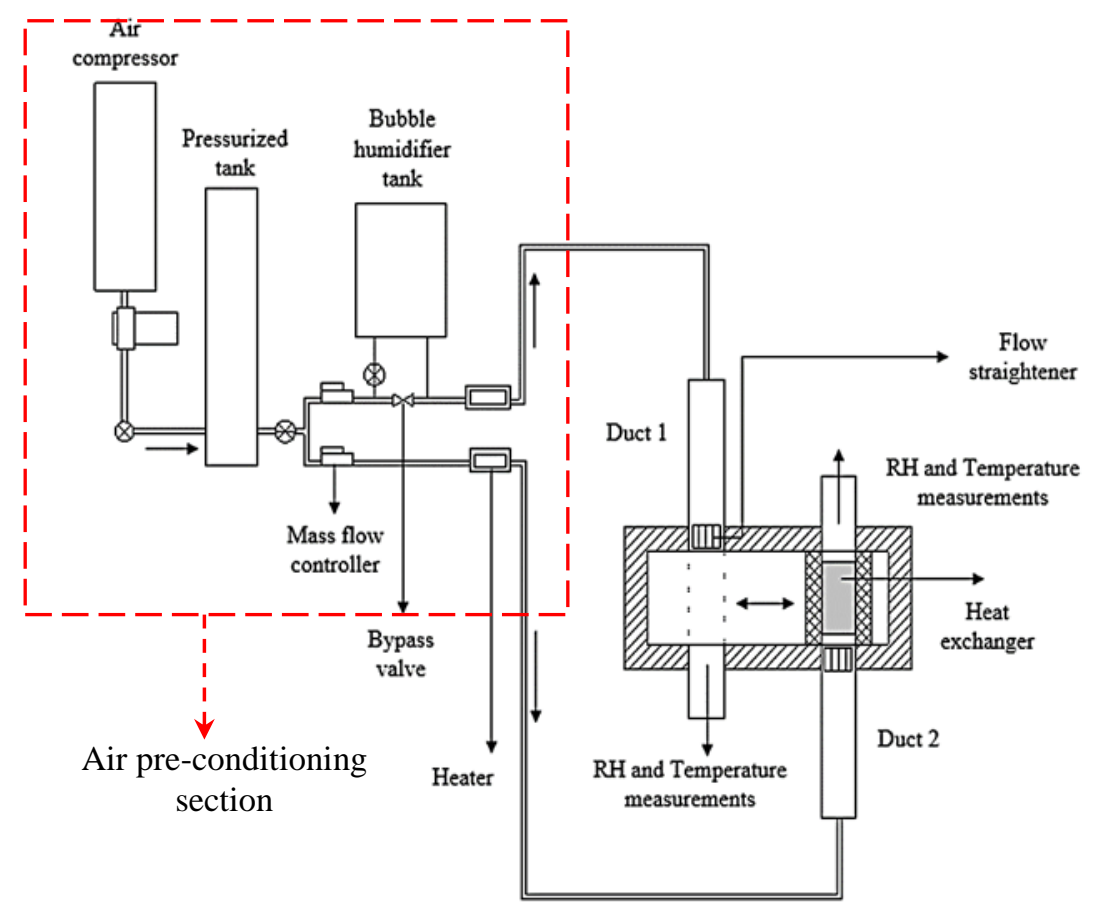

Figure 4 Schematic illustration of the small-scale test facility for the performance evaluation of an energy wheel system

\subsubsection{Single step-change (transient) test}

The following step-wise procedure was followed to conduct a single step-change experiment (Fathieh et al., 2015; Fathieh et al., 2016; Dehabadi et al., 2017). During the pre-conditioning period, conditioned air was passed through each duct for at least an hour until the test facility 
reached a steady-state condition. The steady state is defined by the changes in the temperature and relative humidity measurements achieved within the uncertainty limit of the thermocouples $\left( \pm 0.2^{\circ} \mathrm{C}\right)$ and the humidity sensors $( \pm 1 \%)$, respectively. After this pre-conditioning process, the exchanger was moved from air duct I to air duct II (as shown in Figure 2a) in a fraction of a second using the CGU. In this way, a step-change in the inlet condition was applied to the exchanger. The exchanger remained in this final position until the humidity difference between the inlet and exit measurements was within the uncertainty limit of the sensors $( \pm 1 \%)$. The exchanger's outlet temperature and humidity were noted every second using a National Instruments data acquisition system (NI DAS). Both the temperature and humidity responses of the small-scale facility were then used to calculate the effectiveness of the exchanger using Equations 1 to 4.

\subsubsection{Cyclic test}

The exchanger and the test facility are preconditioned until they reach the steady-state condition, as defined in the single step-change test procedure. Then, continuous step-changes were applied using the CGU. The time period for one cycle was $120 \mathrm{~s}$ (equivalent to $0.5 \mathrm{rpm}$ ). The exchanger's outlet temperature and humidity were noted every second using the NI DAS. After the exchanger had reached equilibrium, Equation 7 was used to calculate the latent effectiveness of the exchanger. The operating conditions of the transient and cyclic experiments are presented in Table 2.

Table 2 Air condition properties and flow rates for the transient adsorption/desorption stepchange test procedure

\begin{tabular}{cccccc}
\hline $\begin{array}{c}\text { Volumetric flow } \\
\text { rate }(\mathrm{L} / \mathrm{min})\end{array}$ & $\begin{array}{c}\text { Temperature air } \\
\left({ }^{\circ} \mathrm{C}\right)\end{array}$ & $\begin{array}{c}\mathrm{P}_{\text {atm }} \\
(\mathrm{bar})\end{array}$ & $\begin{array}{c}\text { Dry air stream } \\
\mathrm{RH}(\%)\end{array}$ & $\begin{array}{c}\text { Humid air } \\
\text { stream RH }(\%)\end{array}$ & $\begin{array}{c}\Delta \mathrm{RH}_{\text {step-change }} \\
(\%)\end{array}$ \\
\hline $15 \pm 1$ & $22.5 \pm 0.5$ & 1.01 & $4 \pm 2$ & $44 \pm 2$ & $40 \pm 2$ \\
\hline
\end{tabular}

\section{RESULTS AND DISCUSSION}

Both the single step-change and cyclic test experiments were conducted using a TTS-CF with the same parallel-plate exchanger used in the TTS-PF. The air condition properties for the experiments are summarized in Table 2. Starch particles isolated from the seeds of carnation starch (Vaccaria hispanica, syn. Saponaria vaccaria) represent the desiccant considered in this study. The detailed sorption and physical characteristics of this desiccant material, as well as the coating method, were described in detail in our previous study (Hossain et al., 2018).

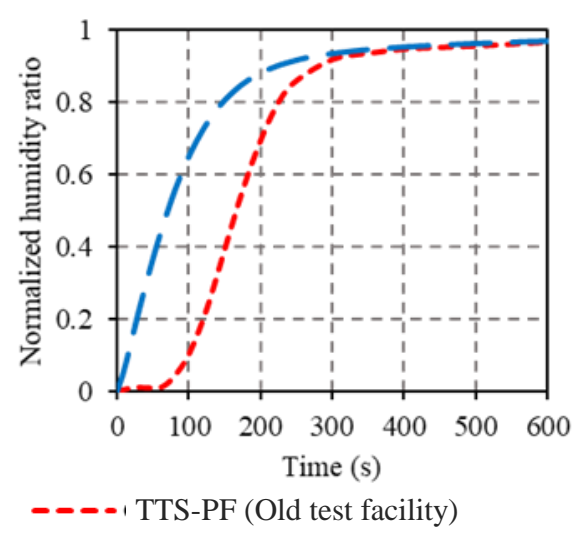

(a)

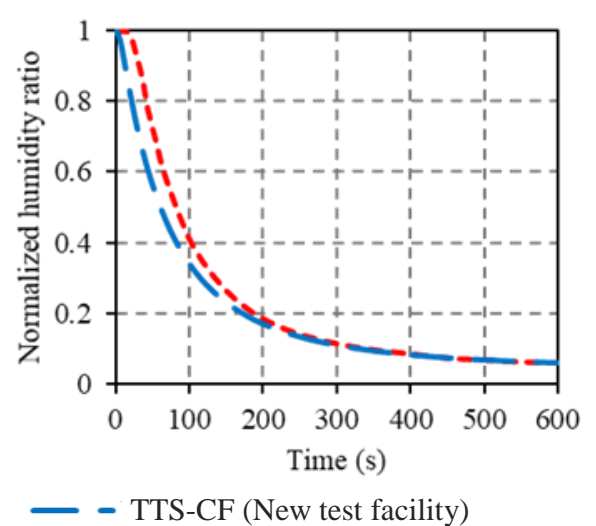

(b)

Figure 5 Normalized humidity ratio for the: (a) adsorption (dehumidification); and (b) desorption (regeneration) processes 
Figure 5 compares the normalized humidity profiles of the starch desiccant-coated exchanger using a TTS-CF (new test facility) and a TTS-PF (old test facility) for the single step-change experiment. It was found that the exchanger responds faster to the step-change using the new test facility than when using the previous test facility ( $c f$. Figure 3 in Fathieh et al., 2016). However, the adsorption/desorption process required ca. $3500 \mathrm{~s}$ to reach a steady-state in both test facilities. The time constants and weighing factors for the adsorption (dehumidification) and desorption (regeneration) processes were estimated by fitting the transient data (Figure 5b) using Equations 3 and 4, respectively. Based on the fitting results, the $N T U_{m}$ was calculated using Equation 2, and finally, the latent effectiveness was estimated using Equation 1. The latent effectiveness of the adsorption and desorption cycles was $62 \%$ and $61 \%$, respectively.

Cyclic experiments with the same operating condition as that applied in the single step-change test were conducted using the same starch-coated exchanger cartridge ( $c f$. Figure 2 in Dehabadi et al., 2017). Figure 6 shows the humidity profile of the exchanger after it reached equilibrium for the initial 10 cycles. During the adsorption process (blue symbols), the coated desiccants initially adsorb moisture from the humid air, and therefore, the humidity of the air at the exchanger's outlet decreases. This continues until the desiccants reach their maximum adsorption capacity. Afterward, the desiccants tend to lose their moisture content, leading to an increase in the humidity at the outlet air stream. During the desorption cycle, the reverse occurs. This process continues during every adsorption-desorption cycle.

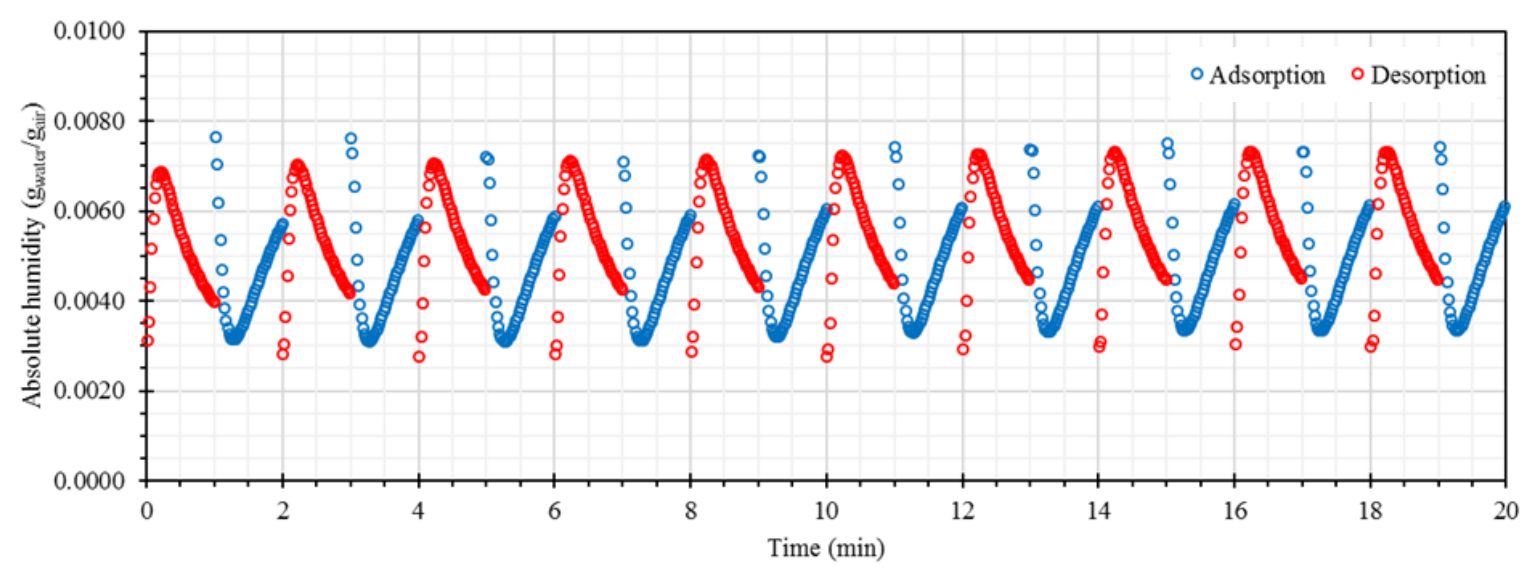

Figure 6 Relative humidity profile of the air streams at the exit of the small-scale exchanger after it reached equilibrium (the initial 10 cycles are shown)

The average humidity ratios of the outlet air stream during the adsorption and desorption cycles are shown in Figures $7 \mathrm{a}$ and $7 \mathrm{~b}$. The latent effectiveness was calculated using Equation 7 based on the average humidity values. The average latent effectiveness for the adsorption and desorption cycles was $62 \%$ and $58 \%$, respectively.
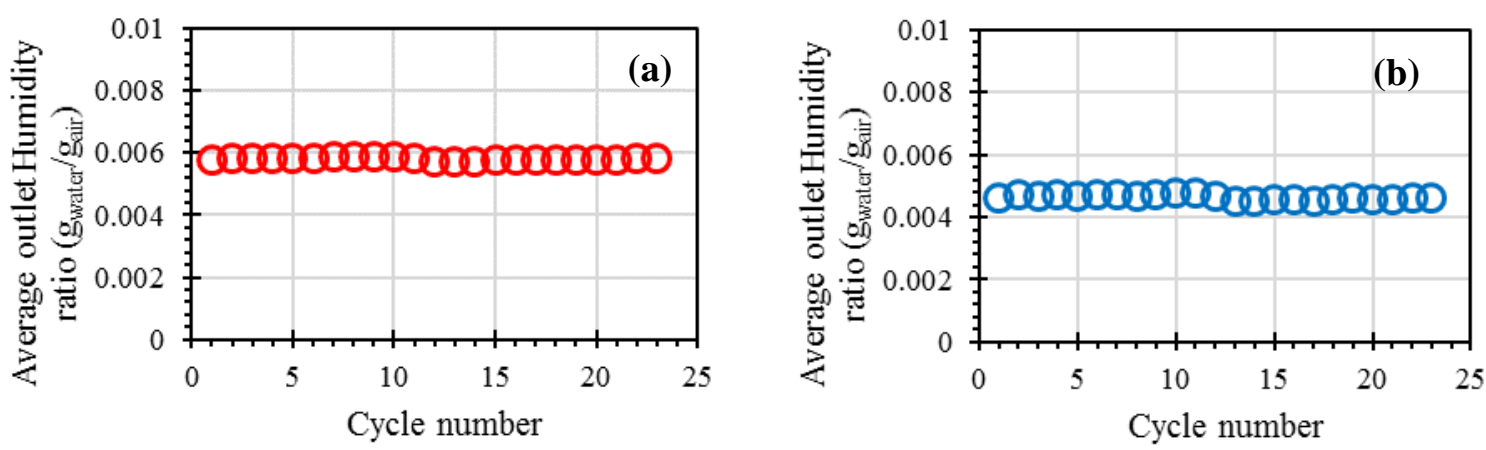

Figure 7 Average humidity ratios at the outlet of the small-scale exchanger for the adsorption (dehumidification) and desorption (regeneration) cycles 
Table 3 summarizes the estimated latent effectiveness values obtained from the single stepchange and cyclic test experiments using the TTS-CF and TTS-PF facilities. The results for the TTS-PF are reported in our previous work (Hossain et al., 2018). Regardless of the test facility and experiment type, it is clear that the values are in good agreement within the experimental uncertainty limits. This favorable correspondence provides a strong indication that not only is the new test facility capable of reproducing the previous data, but it can also be used to simulate and estimate the performance of an energy wheel in a laboratory-scale facility. In terms of the desiccant material, the results further reveal that the starch particles did not exhibit a degradation in their adsorption and desorption performance after 16 months. The temporal stability of the starch desiccant coating provides an assurance as to the material's durability and its promising potential for use in energy wheel applications.

Table 3 Latent effectiveness of energy wheels estimated from the transient characteristic and cyclic experiments over a small-scale parallel exchanger coated with starch particles using

TTS-CF and TTS-PF test facilities

\begin{tabular}{ccccc}
\hline \multirow{2}{*}{ Test facility } & \multicolumn{2}{c}{ Single step-change transient test } & \multicolumn{2}{c}{ Cyclic test } \\
\cline { 2 - 5 } & Adsorption cycle & Desorption cycle & $\begin{array}{c}\text { Adsorption } \\
\text { cycle }\end{array}$ & $\begin{array}{c}\text { Desorption } \\
\text { cycle }\end{array}$ \\
\hline TTS-CF & $62 \pm 3$ & $61 \pm 3$ & $62 \pm 4$ & $58 \pm 4$ \\
TTS-PF $^{8}$ & $67 \pm 3$ & $64 \pm 3$ & N/A & N/A \\
\hline
\end{tabular}

\section{CONCLUSION}

This study focused on the modification of a transient test facility with the aim of achieving the accurate simulation of a full-scale energy wheel operation in a small-scale test environment. A test section was designed and fabricated in order to enable a CF configuration and automated cyclic tests so as to afford the reliable simulation of the energy wheel, as well as to improve the experimental accuracy of the relative humidity measurements. The estimated latent effectiveness of the starch-coated exchanger indicated that not only is the new test facility capable of reproducing the previous data, but it can also be used to simulate and estimate the performance of an energy wheel in a laboratory-scale facility. The transient and cyclic experiments also showed a good level of agreement in terms of the latent effectiveness. This further proved that the transient characteristics obtained from a single step-change test can be used to estimate the performance of an exchanger for adsorption/desorption cycles of various durations. It was additionally found that the starch desiccant particles showed promising durability over a 16month period. Thus, the material could represent a promising desiccant coating for energy wheel applications. Moreover, it is expected that the test facility is capable of providing results capable of accounting for higher rotation frequencies (rpms) after incorporating vacuum bag sampling. Therefore, the upgraded design of this experimental test facility should contribute to further promising advances in the research and development of HVAC systems and industrial AAEEs that reflect typical industrial conditions.

\section{ACKNOWLEDGEMENT}

The Government of Saskatchewan (Ministry of Agriculture), through the Agriculture Development Fund (Project \#20160266), is gratefully acknowledged for supporting this research. The support provided by Daniel Vessey and Blair Cole (College of Engineering Machine Shop, University of Saskatchewan) in terms of the fabrication of the new test facility is also greatly appreciated. 


\section{REFERENCES}

Abe, O.O., Simonson, C.I., Besant, R.W., Shang, W., 2006a. Effectiveness of Energy Wheels from Transient Measurements. Part I: Prediction of Effectiveness and Uncertainty. International Journal of Heat and Mass Transfer, Volume 49(1-2), pp. 52-62

Abe, O.O., Simonson, C.I., Besant, R.W., Shang, W., 2006b. Effectiveness of Energy Wheels from Transient Measurements. Part II: Results and Verification. International Journal of Heat and Mass Transfer, Volume 49(1-2), pp. 63-77

ANSI/AHRI, 2014. Standard 1060: Performance Rating of Air-to-Air Exchangers for Energy Recovery Ventilation Equipment. American National Standard Institute (ANSI) / AirConditioning, Heating \& Refrigeration Institute (AHRI), Arlington County, Virginia, USA

ANSI/ASHRAE, 2013. Standard 84: Method of Testing Air-to-Air Heat/Energy Exchangers. American National Standard Institute (ANSI) / American Society of Heating, Refrigerating and Air-Conditioning Engineers, Inc. (ASHRAE), Arlington County, Virginia, USA

CSA Group, 2018. C439-18: Laboratory Methods of Test for Rating the Performance of Heat/Energy-Recovery Ventilators. CSA Group, Ontario, Canada

Dehabadi, L., Fathieh, F., Wilson, L.D., Evitts, R.W., Simonson, C.J., 2017. Study of Dehumidification and Regeneration in a Starch Coated Energy Wheel. ACS Sustainable Chemistry \& Engineering, Volume 5(1), pp. 221-231

Fathieh, F., Besant, R.W., Evitts, R.W., Simonson, C.J., 2015. Determination of Air-to-Air Heat Wheel Sensible Effectiveness using Temperature Step Change Data. International Journal of Heat and Mass Transfer, Volume 87, pp. 312-326

Fathieh, F., Dehabadi, L., Wilson, L.D., Besant, R.W., Evitts, R.W., Simonson, C.J., 2016. Sorption Study of a Starch Biopolymer as an Alternative Desiccant for Energy Wheels. ACS Sustainable Chemistry \& Engineering, Volume 4(3), pp. 1262-1273

Hossain, M.A., Karoyo, A.H., Dehabadi, L., Fathieh, F., Simonson, C.J., Wilson, L.D., 2018. Starch Particles, Energy Harvesting, and the "Goldilocks Effect". ACS Omega, Volume 3(4), pp. 3796-3803

Shah, R.K., Sekulic, D.P., 2003. Fundamental of Heat Exchanger Design. John Wiley \& Sons Inc., Hoboken, New Jersey, USA

Shang, W., Besant, R.W., 2009a. Effectiveness of Desiccant Coated Regenerative Wheels from Transient Response Characteristics and Flow Channel Properties-Part II. Predicting and Comparing the Latent Effectiveness of Dehumidifier and Energy Wheels using Transient Data and Properties. HVAC\&R Research, Volume 15(2), pp. 346-365

Shang, W., Besant, R.W., 2009b. Performance and Design of Dehumidifier Wheels. HVAC\&R Research, Volume 15(3), pp. 437-460

Wang, Y., Simonson, C.J., Besant, R.W., Shang, W., 2007. Transient Humidity MeasurementsPart I: Sensor Calibration and Characteristics. IEEE Transactions on Instrumentation and Measurement, Volume 56(3), pp. 1074-1079 